\title{
A statistical method for predicting the eccentric load capacity of rectangular concrete filled steel tubular columns
}

\author{
Glib Vatulia ${ }^{1 *}$, Maryna Rezunenko ${ }^{1}$, Dmytro Petrenko ${ }^{1}$, Yevhen Balaka $^{1}$ and Yevhen Orel $^{1}$ \\ ${ }^{1}$ Ukrainian State University of Railway Transport, Structural Mechanics and Hydraulics Department, \\ Feuerbach sq., 7, Kharkiv, 61050, Ukraine
}

\begin{abstract}
The article deals with the integrated approach to the study of the behaviour of rectangular CFST columns under eccentric compression. Such an approach includes the development of methods for assessing the magnitude of the carrying capacity, assessing the degree of reliability and credibility of the obtained results, as well as studying the nature of the development of columns deformations at various stages of loading. The authors developed a mathematical model for calculation of columns carrying capacity under eccentric compression based on statistical methods. Substantial amount of experimental data collected by the world leading laboratories enabled obtaining a regression dependence of the columns carrying capacity that takes into account the impact of the physical and geometric characteristics of such structures. High degree of model confidence is confirmed by a comparative analysis with experimental results that are not involved in the development of the model, as well as with calculations performed according to Eurocode, Japanese and Chinese regulatory documents. The article presents experimental studies of the nature of deformations development on the surface of the steel shell and inside the concrete core of various lengths rectangular columns. As a result of the experimental tests, it was established that the longitudinal strains of the compressed area of the shell have the most significant impact on the bearing capacity of eccentrically compressed steel concrete samples.
\end{abstract}

\section{Introduction}

The issues of improving the quality of construction projects, reducing the cost of construction work, reducing the manufacturing cycle in the development and practical implementation of design solutions will always be relevant. This requires constant updating of the technological base of the construction industry: expanding and intensifying research, introducing advanced technologies, and applying innovative approaches in the design methodology. Many works have considered the researching of strength and reliability of Concrete Filled Steel Tubular (CFST) structures that have been acknowledged in the

\footnotetext{
* Corresponding author: glebvatulya@gmail.com
} 
construction industry [1-9]. Different approaches were also used for predicting the columns load carrying capacity [10-15].

The purpose of this work is developing methods for assessing the carrying capacity of rectangular steel concrete columns under eccentric compression, assessing the degree of confidence and objectivity of the obtained results, and analysing the nature of the destruction of such structures. Previously, the authors already applied this technique in the study of circular and rectangular CFST columns under axial compression [16-18].

To achieve this purpose, the following tasks should be solved:

- development of a mathematical model for assessing the carrying capacity using statistical methods, which reduces the time required to calculate the value of the carrying capacity;

- analysis and verification of the results; and

- conducting experimental studies.

\section{Regression equation}

To solve the described above problem, the authors used the regression and correlation analysis based on experimental results obtained by the leading world laboratories for total 146 observations.

The considered samples have the following characteristics: shell thickness $t \geq 2.5 \mathrm{~mm}$; $80 \leq b \leq 300 \mathrm{~mm} ; 99.4 \leq h \leq 300 \mathrm{~mm}$; ratio $L / b \geq 4$, at $450 \leq L \leq 4910 \mathrm{~mm}$; yield strength of steel $242 \leq \sigma_{y} \leq 746 \mathrm{MPa}$; steel modulus of elasticity $2 \times 105 \leq E_{s} \leq 2.17 \times 105 \mathrm{MPa}$, concrete prism strength $15 \leq f_{c, p r i z m} \leq 83.6 \mathrm{MPa}$, concrete modulus of elasticity $26.8 \leq E_{c} \leq 44.53 \mathrm{MPa}$, eccentricity $0<e<h$.

The resulting regression equation has the form:

$$
\begin{gathered}
\bar{N}=a_{0}+\sum_{i=1}^{5} a_{i} x_{i}=220.745+0.222 x_{1}-3.7 \cdot 10^{-5} x_{2}+0.0027 x_{3}+ \\
+2 \times 10^{-5} x_{4}-14387.2 x_{5}
\end{gathered}
$$

where

$$
\begin{gathered}
x_{1}=(b-2 t)(h-2 t-e) f_{c, p r i z m} / E_{s}, x_{2}=L \sigma_{y} E_{c}, x_{3}=t \sigma_{y} E_{s}, x_{4}=\frac{E_{c}}{\sqrt{t}} L^{1.5} \\
x_{5}=\frac{e}{t^{1.5} \sqrt{L h}}
\end{gathered}
$$

Coefficient of determination $R^{2}$ for the model is 0.982 . Mean approximation error is:

$$
\Delta=\frac{1}{146} \sum_{i=1}^{146} \frac{\left|N_{\text {exp }}^{i}-N_{\text {theor }}^{i}\right|}{N_{\text {exp }}^{i}} 100 \% \approx 7.88 \%
$$

Confidence intervals for each coefficient, found with a probability of $P=0.95$, show how much the obtained regression coefficients can differ from the exact values:

$$
\begin{gathered}
139.994 \leq a_{0} \leq 301.497 \\
0.215 \leq a_{1} \leq 0.229 \\
-4.2 \times 10^{-5} \leq a_{2} \leq-3.3 \times 10^{-5} \\
0.0026 \leq a_{3} \leq 0028 \\
1.45 \times 10^{-7} \leq a_{4} \leq 2.55 \times 10^{-7} \\
-18100.7 \leq a_{5} \leq-10673.7
\end{gathered}
$$

The correspondence of the obtained model to the experimental data, as well as the significance of the regression parameters, is confirmed by the Fisher and Student criteria, respectively.

Fig. 1 shows a histogram of residuals $N_{\text {theor }}-N_{\text {exp }}$. According to the Pearson criterion, the obtained sample at a significance level of $\alpha=0.05$ corresponds to the normal distribution law with zero expected value, and all values fall into the interval $[-3 S ; 3 S]$, 
where $S=112.4$ is the corrected mean square deviation of excess. Also, $73.97 \%$ of the excess fall in the interval $[-S ; S], 95.01 \%$ are in the interval $[-2 S ; 2 S]$.

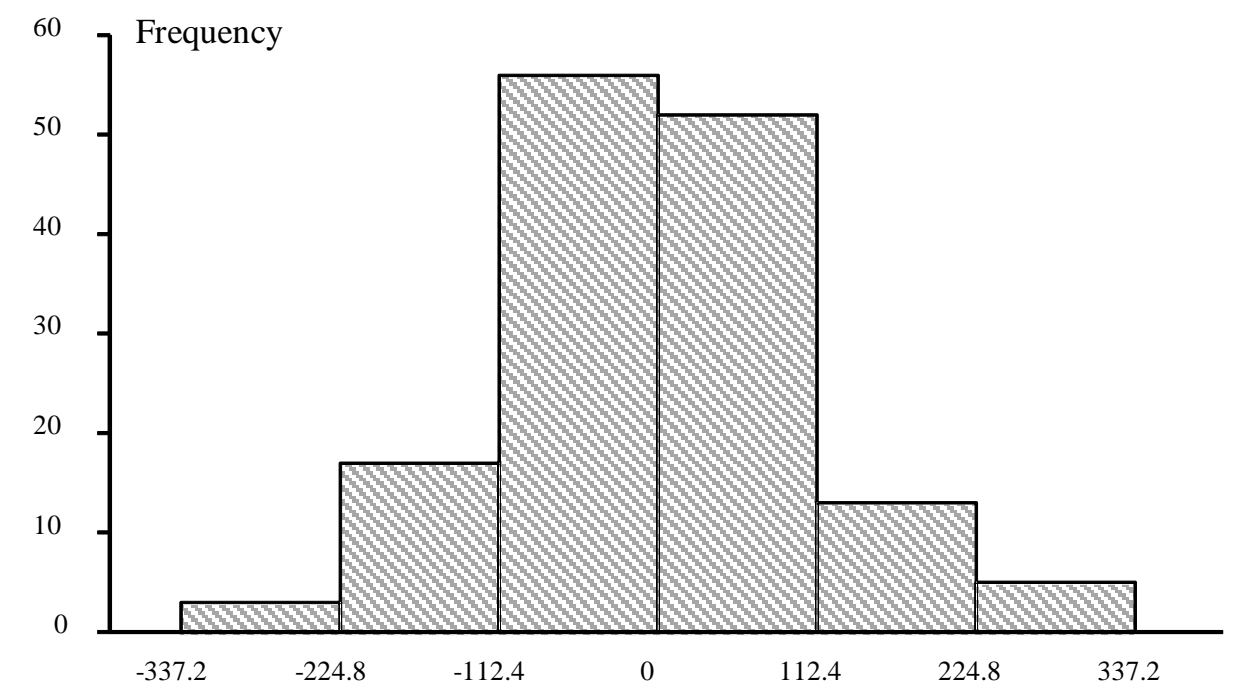

Fig. 1. Histogram of residuals.

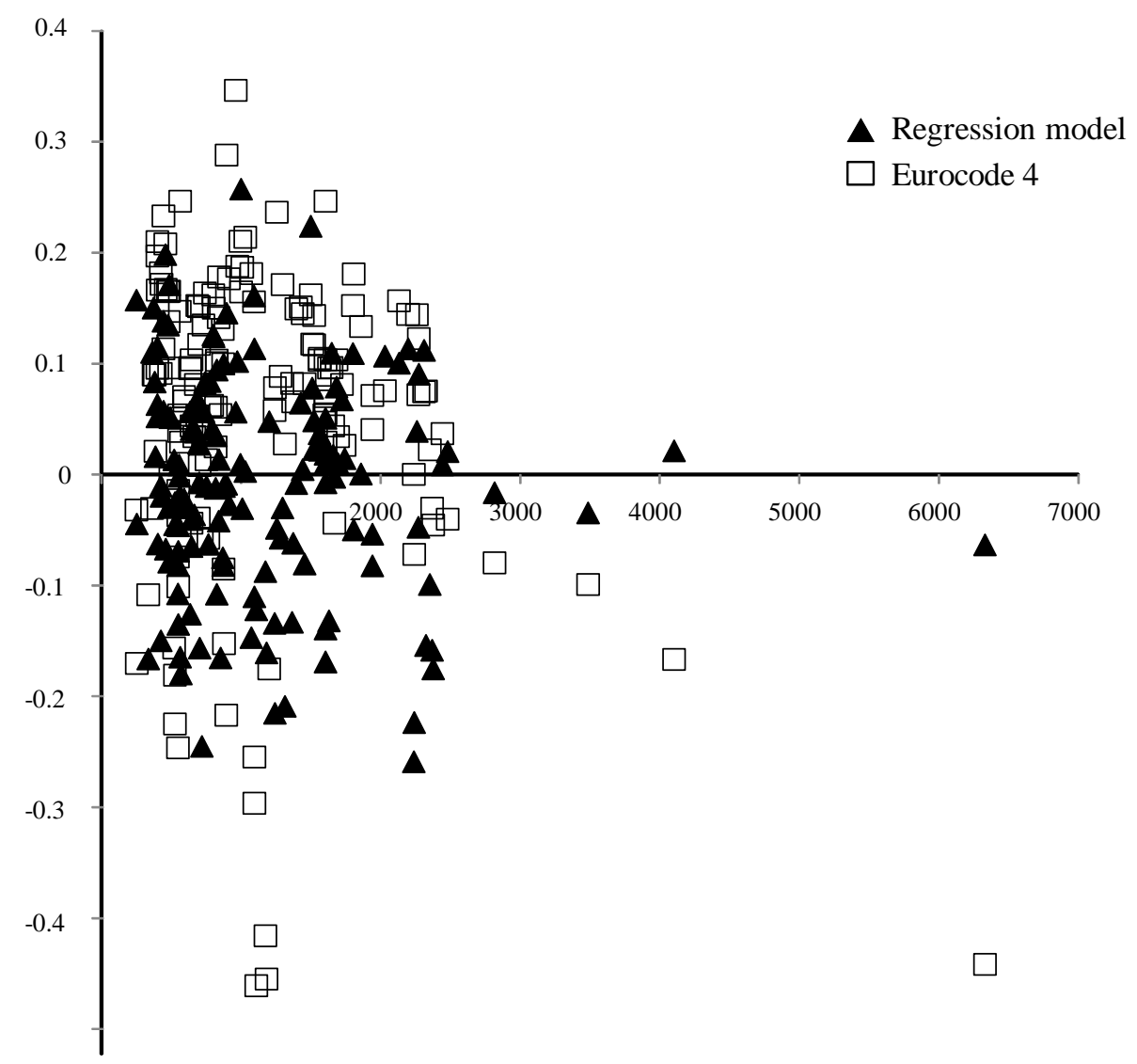

Fig. 2. Comparison of calculation errors. 
Fig. 2 shows a comparative analysis of the calculated value of the carrying capacity of rectangular columns, calculated using the presented methodology and calculation method according to Eurocode 4. In Fig. 2, triangles correspond to the error obtained by the statistical analysis methods, and squares - to those obtained according to Eurocode 4.

Figure 3 shows the dependence of the absolute error $\Delta$ on some parameters of columns. Triangles correspond to the error obtained using the regression model, and squares - to those obtained according to Eurocode 4.
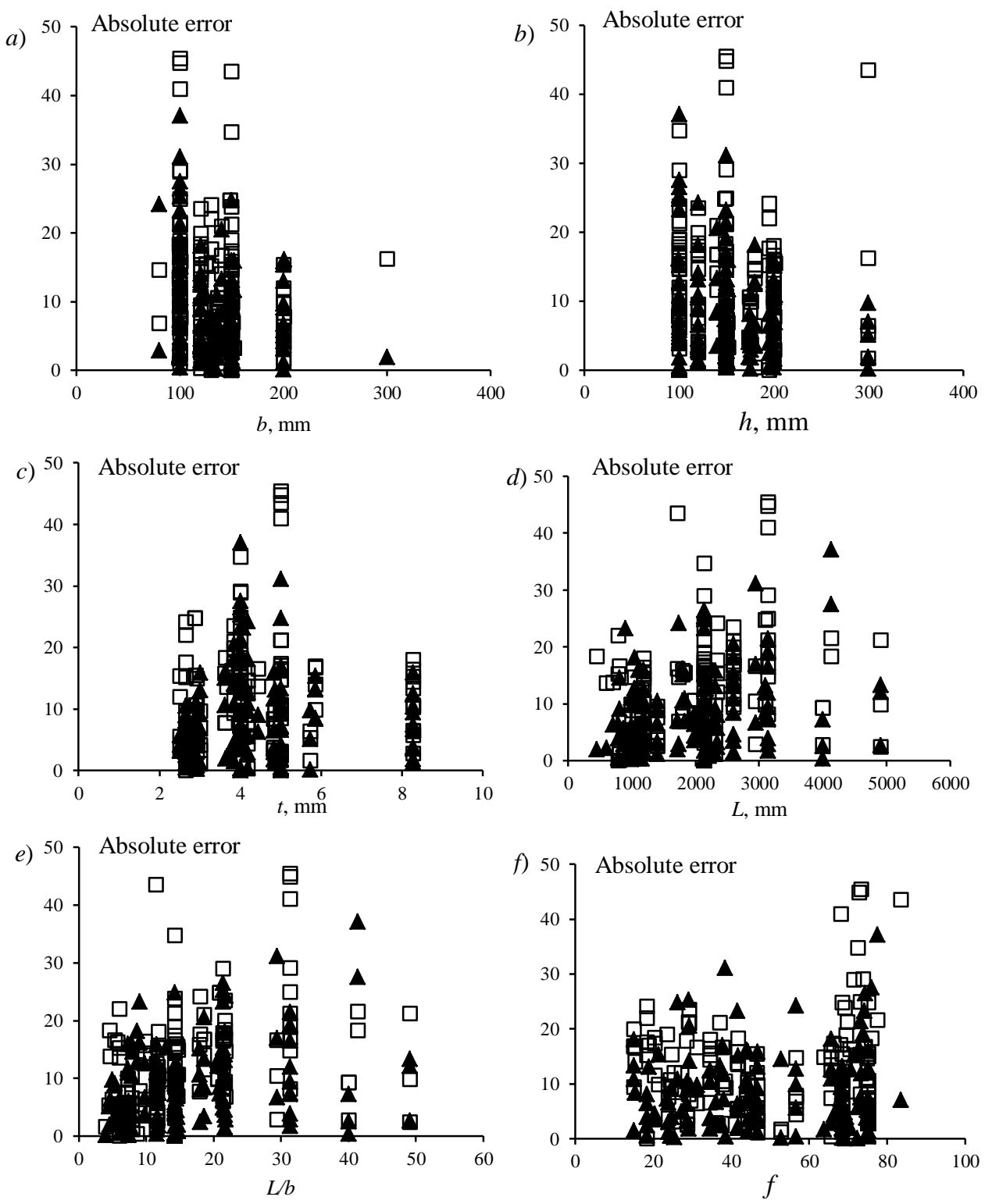

Fig. 3. Dependence of the regression model absolute error: $a$ ) - on $b$; $b$ ) - on $h ; c$ ) on shell thickness $t$; $d$ ) on the columns length $L, e$ ) on $L / b, f$ ) on concrete prism strength $f_{c, p r i z m}$.

Analysis of the factors of the regression model shows the greatest impact (79\%) was exerted by the first factor $(b-2 t)(h-2 t-e) f_{c, \text { prizm }} / E_{s}$. However, to obtain a more accurate understanding of columns behaviour, other characteristics should be taken into 
account (such as column length, yield strength of steel, elastic modulus of steel and concrete), as well as their combined effect. The obtained model was verified by comparing with experimental results, which were not involved in making the model [5].

Table 1 presents the comparative analysis of the obtained theoretical results $\left(N_{\text {theor }}\right)$ with the experimental ones $\left(N_{\text {exp }}\right)$, as well as with the calculations using Eurocode 4 methodologies $\left(N_{E u}\right)$, Japanese $\left(N_{J p n}\right)$ and Chinese $\left(N_{C n}\right)$ regulatory documents [19-22].

Table 1. Comparative analysis.

\begin{tabular}{|c|c|c|c|c|c|c|c|c|c|c|c|c|c|c|}
\hline № & $\begin{array}{c}b, \\
\mathrm{~mm}\end{array}$ & $\begin{array}{c}t, \\
\mathrm{~mm}\end{array}$ & $e / b$ & $\begin{array}{c}\sigma_{y}, \\
\mathrm{MPa}\end{array}$ & $\begin{array}{l}f_{c, p r i z m} \\
\mathrm{MPa}\end{array}$ & $\begin{array}{c}N_{\text {exp }} \\
\mathrm{kN}\end{array}$ & $N_{\text {theor }}$ & $\begin{array}{c}\Delta_{\text {theor }} \\
\%\end{array}$ & $\begin{array}{c}N_{E u}, \\
\mathrm{kN}\end{array}$ & $\begin{array}{c}\Delta_{E U} \\
\%\end{array}$ & $\begin{array}{c}N_{J p n}, \\
\mathrm{kN}\end{array}$ & $\begin{array}{c}\Delta_{J p n} \\
\%\end{array}$ & $\begin{array}{c}N_{C n}, \\
\mathrm{kN}\end{array}$ & $\begin{array}{c}\Delta_{C n} \\
\%\end{array}$ \\
\hline 1 & 160 & 6 & 0.125 & 352 & 39.4 & 1899 & 1884.45 & 1.39 & 1659 & 13.19 & 1757 & 8.06 & 1798 & 5.91 \\
\hline 2 & & & & & & 1936 & 1884.45 & 2.66 & 1659 & 14.31 & 1757 & 9.25 & 1798 & 7.13 \\
\hline 3 & 160 & 6 & 0.125 & 361 & 39.4 & 2093 & 1907.35 & 8.87 & 1756 & 16.10 & 2628 & 25.56 & 1819 & 13.09 \\
\hline 4 & & & & & & 2110 & 1907.35 & 9.60 & 1756 & 16.78 & 2628 & 24.55 & 1819 & 13.79 \\
\hline 5 & 160 & 6 & 0.25 & 360 & 38.1 & 1483 & 1589.83 & 7.20 & 1241 & 16.32 & 1701 & 14.70 & 1558 & 5.06 \\
\hline 6 & & & & & & 1550 & 1589.83 & 2.57 & 1241 & 19.94 & 1701 & 9.74 & 1558 & 0.52 \\
\hline 7 & 160 & 6 & 0.25 & 351 & 38.1 & 1569 & 1566.86 & 0.14 & 1555 & 0.89 & 1231 & 21.54 & 1540 & 1.85 \\
\hline 8 & & & & & & 1503 & 1568.47 & 4.36 & 1555 & 3.46 & 1231 & 18.10 & 1540 & 2.46 \\
\hline 9 & 160 & 6 & 0.5 & 360 & 39.5 & 1011 & 1180.89 & 16.80 & 798 & 21.07 & 887 & 12.27 & 1269 & 25.52 \\
\hline 10 & & & & & & 1080 & 1180.89 & 9.34 & 798 & 26.11 & 887 & 17.87 & 1269 & 17.50 \\
\hline 11 & 160 & 6 & 0.5 & 355 & 39.5 & 1046 & 1201.24 & 14.84 & 888 & 15.11 & 1391 & 32.98 & 1261 & 20.55 \\
\hline 12 & & & & & & 1103 & 1201.24 & 8.91 & 888 & 19.49 & 1391 & 26.11 & 1261 & 14.32 \\
\hline 13 & 160 & 6 & 0.75 & 358 & 35.3 & 727 & 771.34 & 6.10 & 731 & 0.55 & 905 & 24.48 & 991 & 36.31 \\
\hline 14 & & & & & & 739 & 771.34 & 4.38 & 731 & 1.08 & 905 & 22.46 & 991 & 34.10 \\
\hline 15 & 160 & 6 & 0.75 & 352 & 35.3 & 763 & 792.13 & 3.82 & 825 & 8.13 & 745 & 2.36 & 983 & 28.83 \\
\hline 16 & & & & & & 793 & 792.13 & 0.11 & 825 & 4.04 & 745 & 6.05 & 983 & 23.96 \\
\hline 17 & 180 & 8 & 0.125 & 348 & 55.1 & 3153 & 2799.74 & 10.58 & 2915 & 6.90 & 3799 & 21.34 & 2940 & 6.10 \\
\hline 18 & & & & & & 2976 & 2799.74 & 5.92 & 2915 & 2.05 & 3799 & 27.65 & 2940 & 1.21 \\
\hline 19 & 180 & 8 & 0.25 & 357 & 50.1 & 2329 & 2465.73 & 5.87 & 1945 & 16.49 & 3071 & 31.86 & 2452 & 5.28 \\
\hline 20 & & & & & & 2489 & 2465.73 & 0.93 & 1945 & 21.86 & 3071 & 23.38 & 2452 & 1.49 \\
\hline
\end{tabular}




\section{Experimental tests}

To study the nature of the destruction, experimental studies of steel concrete columns with lengths of 500, 1000, 1500 and $2000 \mathrm{~mm}$ were conducted. The shells of the columns had a thickness of $t=2 \mathrm{~mm}$, and were filled with C16/20 concrete.

The steel with a yield strength of $\sigma_{y}=240 \mathrm{MPa}$ was used to manufacture the shell. Once the metal shells were produced, they were filled with concrete mixture in an upright position with layer-by-layer compaction with a plate vibrator.

Prototypes (Fig. 4) tested for eccentric compression were labelled as follows:

SBK-5v, 6v, 7v, 8v; SBK-1.0-4v, 5v, 6v; SBK-1.5-3v, 4v, 5v, 6v; SBK-2.0-3v, 4v, 5v, $6 \mathrm{v}-100 \times 100 \mathrm{~mm}$ square steel concrete columns;

SBP-5v, 6v, 7v, 8v - 150×100 mm rectangular steel concrete columns.

Steel concrete columns were tested on IP-2000 hydraulic press in the laboratory of Structural Mechanics and Hydraulics Department of the Ukrainian State University of Railway Transport. All samples were brought to destruction, Fig. 4.

a)

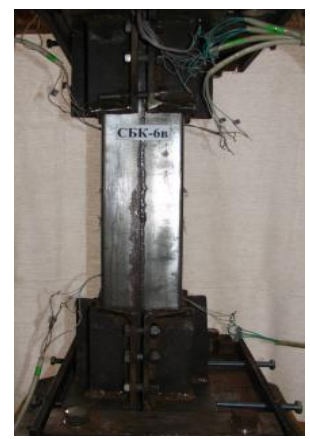

b)

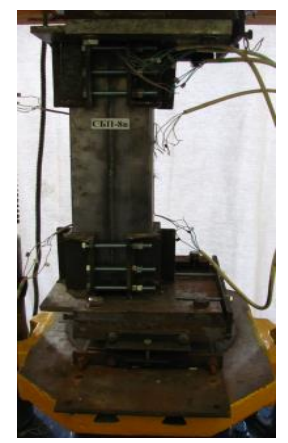

Fig. 4. Steel concrete columns before testing: $a$ ) square column, $b$ ) rectangular column.

Fig. 5 shows the steel concrete columns after testing. It should be noted that the tested samples did not lose their carrying capacity instantly, as it is the case with reinforced concrete structures. After significant deformations, they still withstood a significant load for a long time.

a)

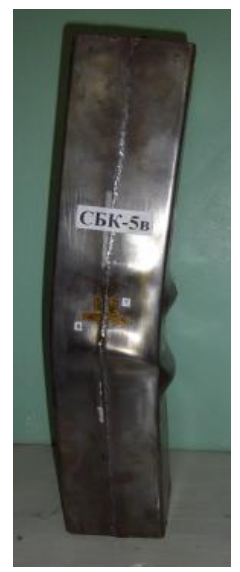

b)

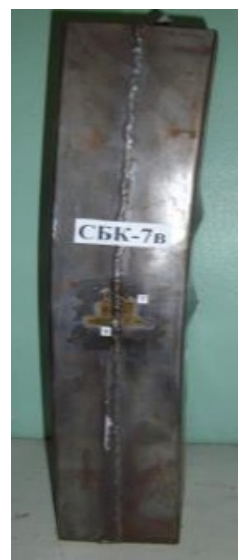

c)

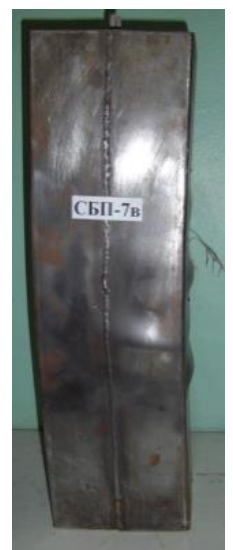

d)

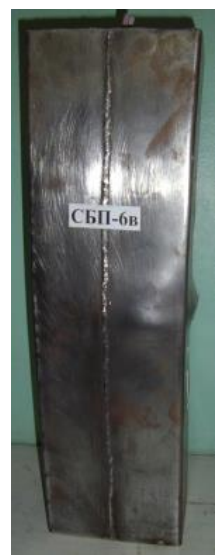

Fig. 5. Steel concrete columns after testing: $a$ ), $b$ ) square column, $c$ ), $d$ ) rectangular column. 
Analysis was carried out after the shell of the steel concrete columns was dismantled. The appearance of the concrete core and steel shell after dismantling is shown in Fig. 6.

Analysis of the disintegration nature of the concrete core conducted after dismantling shows that in points of local disintegration of the concrete core, concrete is detached from the shell. At this moment, a sharp redistribution of stresses occur between the components of the steel concrete element, resulting in the loss of stability of the steel shell and appearance of transverse corrugations.

a)

b)

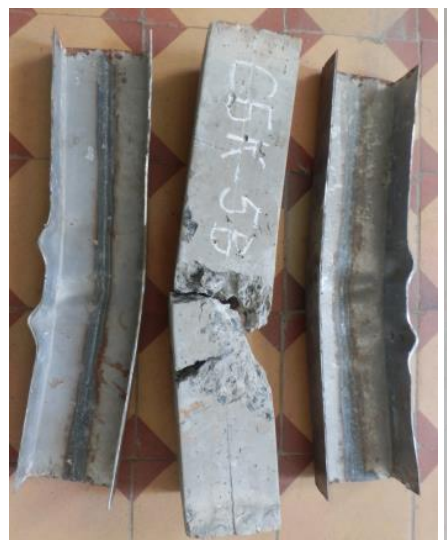

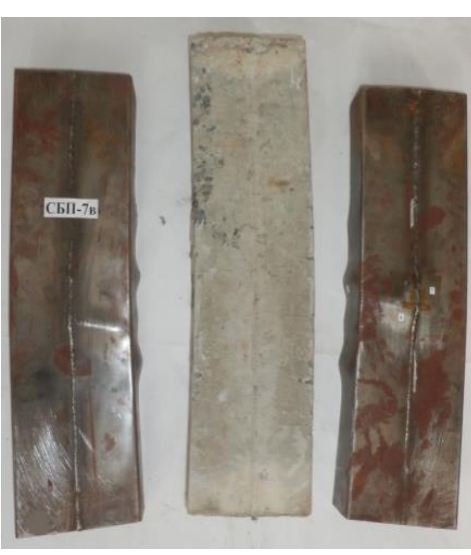

c)

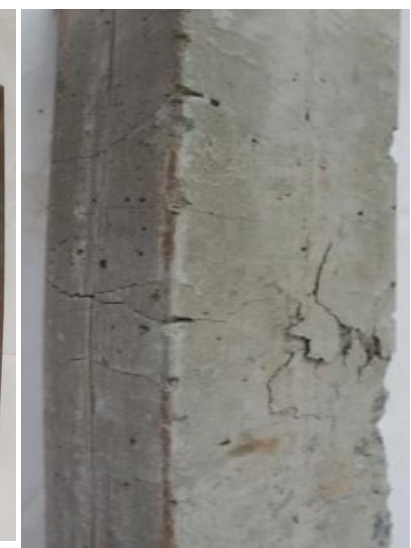

Fig. 6. Concrete core and steel shell after dismantling the columns: $a$ ) square column, $b$ ), c) rectangular column.

The nature and type of destruction of eccentrically compressed samples were generally similar to that of centrally compressed steel concrete elements. The difference was that with eccentric application of the load, corrugations formed on the surface of the steel shell only in the maximum compression area.

At the first stage, there was elastic work of the concrete core and steel shell. The increment of the deflections and deformations of the average sectional height is practically proportional to the increase in load.

At the second (elastic plastic) stage, the shell metal in the compressed area began to yield. The dependences of deformations and deflections on the load became nonlinear. When longitudinal deformations in the steel shell reach values of about $(1000 \div 1200) \cdot 10^{-6}$, the elastic plastic stage of work of the samples ended.

At the third stage of (plastic) deformations of the element in the longitudinal and transverse directions increased sharply. At the plastic stage of work of steel concrete samples, most of the resistance strain gages that were in the compressed area failed due to excessive deformations of concrete and steel.

The fourth stage of work was the destruction of eccentrically compressed steel concrete elements, began with the formation of longitudinal corrugations in the maximum compression area, and ended with a sharp increase in the curvature of the element in the plane of the bending moment from the load.

As a result of the experimental tests, it was established that the longitudinal deformations of the compressed area of the shell most significantly affect the carrying capacity of the eccentrically compressed steel concrete samples. At the moment of stability loss, the shell metal reaches the yield limit only in the middle part of the compressed area.

It should be noted that in the studied steel concrete samples, the absolute magnitude of deformation of the shell of the stretched area are much lower than those of the compressed area, their values do not reach the yield limit even when samples are destroyed. So, the 
compressed area is of crucial importance to characterize the stress strain state of flexible eccentrically compressed steel concrete elements.

The process of stress redistribution between the tube and concrete during testing of the steel concrete samples with a short-term load depends to a large extent on the relative length of the elements, the eccentricity of the external load, and on the magnitude of the external load.

The experimental studies carried out by the authors revealed the effect of the geometric dimensions of the steel concrete columns and physic-mechanical characteristics of the materials on the carrying capacity and deformability of columns (Table 2).

Table 2. Test results of steel concrete columns.

\begin{tabular}{|c|c|c|c|c|c|c|c|}
\hline Sample No. & $L, \mathrm{~mm}$ & $e, \mathrm{~mm}$ & $N_{\text {exp }}, \mathrm{kN}$ & Sample No. & $L, \mathrm{~mm}$ & $e, \mathrm{~mm}$ & $N_{\text {exp }}, \mathrm{kN}$ \\
\hline SBK-5v & 500 & 25 & 158 & SBK-1.0-6v & 1000 & 50 & 79 \\
\hline SBK-6v & 500 & 25 & 145 & SBK-1.5-3v & 1500 & 25 & 135 \\
\hline SBK-7v & 500 & 50 & 82 & SBK-1.5-4v & 1500 & 25 & 128 \\
\hline SBK-8v & 500 & 50 & 91 & SBK-1.5-5v & 1500 & 50 & 93 \\
\hline SBP-5v & 500 & 50 & 200 & SBK-1.5-6v & 1500 & 50 & 89 \\
\hline SBP-6v & 500 & 50 & 211 & SBK-2.0-3v & 2000 & 25 & 147 \\
\hline SBP-7v & 500 & 75 & 155 & SBK-2.0-4v & 2000 & 25 & 88 \\
\hline SBP-8v & 500 & 75 & 186 & SBK-2.0-5v & 2000 & 50 & 56 \\
\hline SBK-1.0-4v & 1000 & 25 & 191 & SBK-2.0-6v & 2000 & 50 & 65 \\
\hline SBK-1.0-5v & 1000 & 50 & 148 & & & & \\
\hline
\end{tabular}

\section{Conclusions}

1. A mathematical model has been developed to assess the effect of the geometric and physical characteristics of a rectangular column on the carrying capacity under eccentric compression.

2. High degree of model reliability is confirmed by the comparative analysis and results verification.

3. Experimental studies have been conducted to investigate the nature of the deformations development on the surface of the steel shell and inside the concrete core of rectangular columns at various stages of loading.

\section{References}

1. L. Han, Concrete filled steel tubular structure, theory and practice (Science press, Beijing, 2007)

2. E.D. Chikhladze, G.L. Vatulia, Y.P. Kitov, Basis for calculation and design of composite and steel-concrete constructions, Transport of Ukraine, 104 (2006)

3. J. Wang, F. Wang, Q. Shen, Thin-Walled Structures, 135, 210-226 (2019)

4. T. Yamamoto, J. Struct. Constr. Eng., Transactions of AIJ, 561, 237-244 (2002)

5. A. L. Krishan, A. S. Melnitchuk, News of KSUAE, Kazan, 3 (29), 6-50 (2014)

6. L. I. Storozhenko, D. A. Ermolenko, O. I. Lapenko, Tube confined concrete (ASMI, Poltava, 306, 2010) 
7. G. L. Vatulia, D. H. Petrenko, M. A. Novikova, Scientific Bulletin of National Mining University, 6, 97-102 (2017)

8. I. Nishiyama, S. Morino, K. Sakino, H. Nakahara, Summary of Research on ConcreteFilled Structural Steel Tube Column System Carried Out Under The US-JAPAN Cooperative Research Program on Composite and Hybrid Structures (Tokyo, 176 2002)

9. Q. Q. Liang, B. Uy, J. Y. R. Liew, Australian Journal of Structural Engineering, 7(2), 145-155 (2007)

10. B. Evirgen, A.Tuncan, K. Taskin, Thin-Walled Struct. 80, 46-56 (2014)

11. A. Kuranovas, D. Goode, A. Kvedaras, S. Zhong, Journal of Civil Engineering and Management, 15(1), 21-33 (2009)

12. A. S. Saadoon, K. Z. Nasser, I. Q. Mohamed, Eng. Technol. J. 30, 3328-3340 (2012)

13. X. Lyu, Y. Xu,; Q. Xu, Y. Yu, Materials, 12, 1098 (2019)

14. L. Q. Zheng, S. L. Guo, J. Z. Zhou, Appl. Mech. Mater. 405-408, 1041-1045 (2013)

15. Y. Wang, Z. Q. Liu, M. Zhang, Appl. Mech. Mater. 368-370, 1095-1098 (2013)

16. G. Vatulia, M. Rezunenko, Ye Orel, D. Petrenko, DYN-WIND'2017, MATEC Web of Conferences, 107, 00051 (2017)

17. G. Vatulia, M. Rezunenko, D. Petrenko, S. Rezunenko, Civil and Environmental Engineering, 14, 76-83 (2018)

18. G. Vatulia, M. Rezunenko, Ye Orel, N. Panchenko, BulTrans-2018, MATEC Web of Conferences, 234, 04002 (2018)

19. Design of composite steel and concrete structures - Part 1-1: General Rules and Rules for Bridges. EN 1994-1: 2001. Eurocode 4 (Brussels, 96, 2006)

20. Recommendations for design and construction of concrete filled steel tubular structures, (Architectural Institute of Japan (AIJ), Tokyo, 333, 1997)

21. Design Regulation of Composite Structures. Square CFST Members(S), GJB4142-2000 (Beijing, 2001)

22. X. M. Yu, B. C. Chen, Int. J. Civ. Environ. 11, 20-39 (2011) 